\title{
Correlation between the Degree of Liver Fibrosis and Driving Test Alterations as an Indicator of Minimal Hepatic Encephalopathy
}

\author{
Carlos Tornero*, Simona Cioaia, Marina Llopis, Ana Ventura \\ Internal Medicine, Hospital Francesc de Borja, Gandia, Spain \\ Email: ${ }^{*}$ tornero car@gva.es
}

Received 22 February 2015; accepted 10 April 2015; published 15 April 2015

Copyright (C) 2015 by authors and Scientific Research Publishing Inc.

This work is licensed under the Creative Commons Attribution International License (CC BY). http://creativecommons.org/licenses/by/4.0/

\section{(c) (i) Open Access}

\begin{abstract}
Minimal hepatic encephalopathy is a subclinical disorder in patients with liver cirrhosis that may have an impact upon driving capacity. This study in highly selected patients without other confounding factors examines whether there is a relationship between the degree of liver fibrosis as determined by Fibroscan exploration and the driving test scores. Using the ASDE DRIVER-TEST $\mathrm{N}$-845 system, validated for obtaining the driving license in Spain, we assessed the calculation of distances and time, bimanual visual-motor coordination, reaction time to different stimuli, concentrated attention, and resistance to monotony. The data were processed using the SPSS statistical package, with an analysis of the correlation between the degree of fibrosis and the test scores based on the Spearman statistic and the comparison of means (Mann-Whitney U-test). We found no alterations in driving capacity in patients diagnosed of hepatitis $C$ with different degrees of early stage fibrosis or cirrhosis.
\end{abstract}

\section{Keywords}

Minimal Hepatic Encephalopathy, Driving

\section{Introduction}

Hepatic encephalopathy is a well known and easily identifiable complication of advanced liver cirrhosis (LC). In recent years, there has been increased interest in a new and less easily identifiable condition known as minimal

${ }^{*}$ Corresponding author.

How to cite this paper: Tornero, C., Cioaia, S., Llopis, M. and Ventura, A. (2015) Correlation between the Degree of Liver Fibrosis and Driving Test Alterations as an Indicator of Minimal Hepatic Encephalopathy. Open Journal of Gastroenterology, 5, 28-30. http://dx.doi.org/10.4236/ojgas.2015.54006 
hepatic encephalopathy (MHE), corresponding to neurocognitive dysfunction found in a large proportion of patients with LC, and characterized by normal neurological exploratory findings but with altered psychometric and neurological test results [1]-[5]. MHE can have a strong impact upon patient quality of life, and can affect daily life activities, with an increased incidence of driving accidents associated to increased alterations of the psychometric test results [6]-[8]. Based on the experienced gained with the use of Fibroscan exploration in other types of patients [9]-[11], the present study was carried out to determine whether progressive liver fibrosis detected by this technique is correlated to the results obtained in the driving tests validated in Spain, with the aim of defining a cutoff point beyond which driving capacity may be altered and driving therefore should be avoided.

\section{Material and Methods}

A selection was made of all the patients with a Fibroscan exploration made in the last year for evaluating fibrosis secondary to liver disease produced by the hepatitis C virus (HCV). Patients with HIV infection, neurological disorders, coexisting alcoholism or treatments capable of interfering with the study tests were excluded. A total of 26 patients were finally included. A summarize of the characteristics of the subjects are sown in Table 1. Using the ASDE DRIVER-TEST N-845 system, validated for obtaining the driving license in Spain, we assessed the calculation of distances and time, bimanual visual-motor coordination, reaction time to different stimuli, concentrated attention, and resistance to monotony. The test is preceded by a learning phase to ensure motivation and understanding. The reference values corresponding to the Spanish general population, and cutoff points defining driving aptitude, were obtained from the manufacturer of the system [12] [13]. We also collected clinical and laboratory test data on the patients, and classified LC based on the CHILD scale. The data were processed using the SPSS statistical package, with an analysis of the correlation between the degree of fibrosis and the test scores based on the Spearman statistic and the comparison of means (Mann-Whitney U-test) between subjects with moderate-advanced fibrosis $(\mathrm{F} \geq 9.5 \mathrm{kPa})$ and patients with mild fibrosis $(<9.5 \mathrm{kPa})$.

\section{Results}

Twenty-six patients were evaluable to the effects of analysis: 55\% males, mean age 53 years (SD 11.2), with medium or higher level education in $68 \%$ of the cases, and regular driving activity in $68 \%$. Eight patients had moderate-advanced fibrosis (all in initial stages of cirrhosis; CHILD A).

No significant correlation was found between the degree of fibrosis and any of the parameters measured in the driver test. Likewise, no differences in the mean scores were observed on stratifying the patients into individuals with moderate-advanced fibrosis and subjects with mild fibrosis. On individually analyzing a single patient with mild fibrosis, the scores were seen to be below the minimum acceptable level in three of the tested areas-this being enough to fail the driving test.

\section{Comments}

Driving is a complex activity requiring attention, the calculation of distances and speed, and responses to stimulithese functions being assessed by psychometric tests. Such functions could be progressively impaired in patients with minimal hepatic encephalopathy, thereby affecting the capacity to drive. In this regard, different degrees of liver fibrosis may be expected to alter liver function, which in turn would be reflected by gradual worsening of the driving skill test results.

We recorded no relevant alterations in driving capacity. This might be explained by the fact that our study involved a highly selected group of patients with HCV coinfection in the absence of other factors capable of altering the tests results, and in early and scantly symptomatic stages of the disease. However, it is precisely in patients of this kind where it is important to know whether there is some degree of fibrosis beyond which the presence of MHE affects driving capacity.

In such patients, who give rise to doubts in clinical practice, we observed no alterations in driving capacity that might increase the risk of traffic accidents. Patients with liver disease produced by hepatitis $\mathrm{C}$ and presenting mild or moderate fibrosis or early stage cirrhosis showed no relevant alterations in the driver test results. As limitations of our study it is done in patients with low degrees of liver fibrosis so the results may not be applicable to those with advanced cirrosis. 
Table 1. Characteristics of the study population.

\begin{tabular}{cc}
\hline Age & $53(\mathrm{SD} 11.2)$ \\
Males & $55 \%$ \\
Level of education & Low $=9$ \\
$\mathrm{~N}=26$ & Medium $=11$ \\
& High $=6$ \\
Regular driving & $68 \%$ \\
Fibrosis (Kp) & $10.3(\mathrm{SD} 9.1)$ \\
& $\geq 7.4 \mathrm{n}=17$ \\
& $\geq 8.6 \mathrm{n}=12$ \\
& $\geq 9.5 \mathrm{n}=8$ \\
& $\geq 12.5 \mathrm{n}=4$ \\
\hline
\end{tabular}

In conclusion, and recognizing the limits imposed by the small sample size, we observed no alterations in driving skill in our highly selected group of patients coinfected with HCV and with different degrees of fibrosis or early stage cirrhosis.

\section{References}

[1] Wang, J.-Y., Zhang, N.-P., Chi, B.-R., Mi, Y.-Q., Meng, L.-N., et al. (2013) Prevalence of Minimal Hepatic Encephalopathy and Quality of Life Evaluations in Hospitalizad Cirrhotic Patients in China. World Journal of Gastroenterology, 19, 4984-4991. http://dx.doi.org/10.3748/wjg.v19.i30.4984

[2] Maldonado-Garza, H.J., Vázquez-Elizondo, G., Gaytán-Torres, J.O., Flores-Rendón, A.R., Cárdenas-Sandoval, M.G. and Bosques-Padilla, F.J. (2011) Prevalence of Minimal Hepatic Encephalopathy in Cirrhotic Patients. Annals of Hepatology, 10, S40-S44.

[3] Bajaj, J.S. (2008) Management Options for Minimal Hepatic Encephalopathy. Expert Review of Gastroenterology and Hepatology, 2, 785-790. http://dx.doi.org/10.1586/17474124.2.6.785

[4] Kharbanda, P.S., Saraswat, V.A. and Dhiman, R.K. (2003) Minimal Hepatic Encephalopathy: Diagnosis by Neuropsychological and Neurophysiologic Methods. Indian Journal of Gastroenterology, 22, S37-S41.

[5] Dhiman, R.K. and Chawla, Y.K. (2009) Minimal Hepatic Encephalopathy. Indian Journal of Gastroenterology, 28, 5-16. http://dx.doi.org/10.1007/s12664-009-0003-6

[6] Bajaj, J.S., Saeian, K., Schubert, C.M., Hafeezullah, M., Franco, J., et al. (2009) Minimal Hepatic Encephalopathy Is Associated with Motor Vehicle Crashes: The Reality beyond the Driving Test. Hepatology, 50, 1175-1183. http://dx.doi.org/10.1002/hep.23128

[7] Wein, C., Koch, H., Popp, B., Oehler, G. and Schauder, P. (2004) Minimal Hepatic Encephalopathy Impairs Fitness to Drive. Hepatology, 39, 739-745. http://dx.doi.org/10.1002/hep.20095

[8] Bajaj, J.S., Pinkerton, S.D., Sanyal, A.J. and Heuman, D.M. (2012) Diagnosis and Treatment of Minimal Hepatic Encephalopathy to Prevent Motor Vehicle Accidents: A Cost-Effectiveness Analysis. Hepatology, 55, 1164-1171. http://dx.doi.org/10.1002/hep.25507

[9] Tornero, C., Ventura, A., Bourguet, M. and Poquet, I. (2012) Evaluation of Driving Ability among Residents after the Duty Shift. Accident Analysis \& Prevention, 17, 182-183. http://dx.doi.org/10.1016/j.aap.2012.01.007

[10] Tornero, C., Poquet, I., Bourguet, M., Gomis-Pajares, F., Ventura, A. and Mafe, M.C. (2012) Driving Skills in HIV Infected Patients Well Controlled with Antiretroviral Therapy. World Journal of AIDS, 2, 122-125. http://dx.doi.org/10.4236/wja.2012.23017

[11] Poquet, I., Bourguet, M., Cioaia, S. and Tornero, C. (2014) Alteraciones de las habilidades para la conducción en pacientes que inician tratamiento con efavirez. Enfermedades Infecciosas y Microbiología Clínica, 32, 56-60. http://dx.doi.org/10.1016/j.eimc.2013.05.008

[12] Monterde, H. (2005) Real Decreto 772/97 ASDE Driver-Test N-845. Examen psicológico de conductores en España con equipos normalizados.

[13] Badenes Guia, D., Casas Hernanz, L., Aguilar Barberà, M. and Cejudo Bolivar, J.C. (2007) Discriminación de la valoración de la capacidad de conducción de vehículos en personas con diagnóstico de deterioro cognitivo ligero y demencia en los exámenes de conducción normalizados. Mafre Medicina, 18, 98-107. 